Undergraduate Students, Population, Health \& Wellness

\title{
West Nile Virus Seroprevalence Among Qatari And Immigrant Populations Residing In Qatar
}

Hasna Kunhipurayil, Muna Ahmed

Supervised by : Dr. Gheyath Nasrallah

Biomedical Science Department, College of Health Sciences, Qatar University, Doha, Qatar, Biomedical Research Center, Qatar University, Doha, Qatar

\begin{tabular}{|c|}
\hline \\
\hline 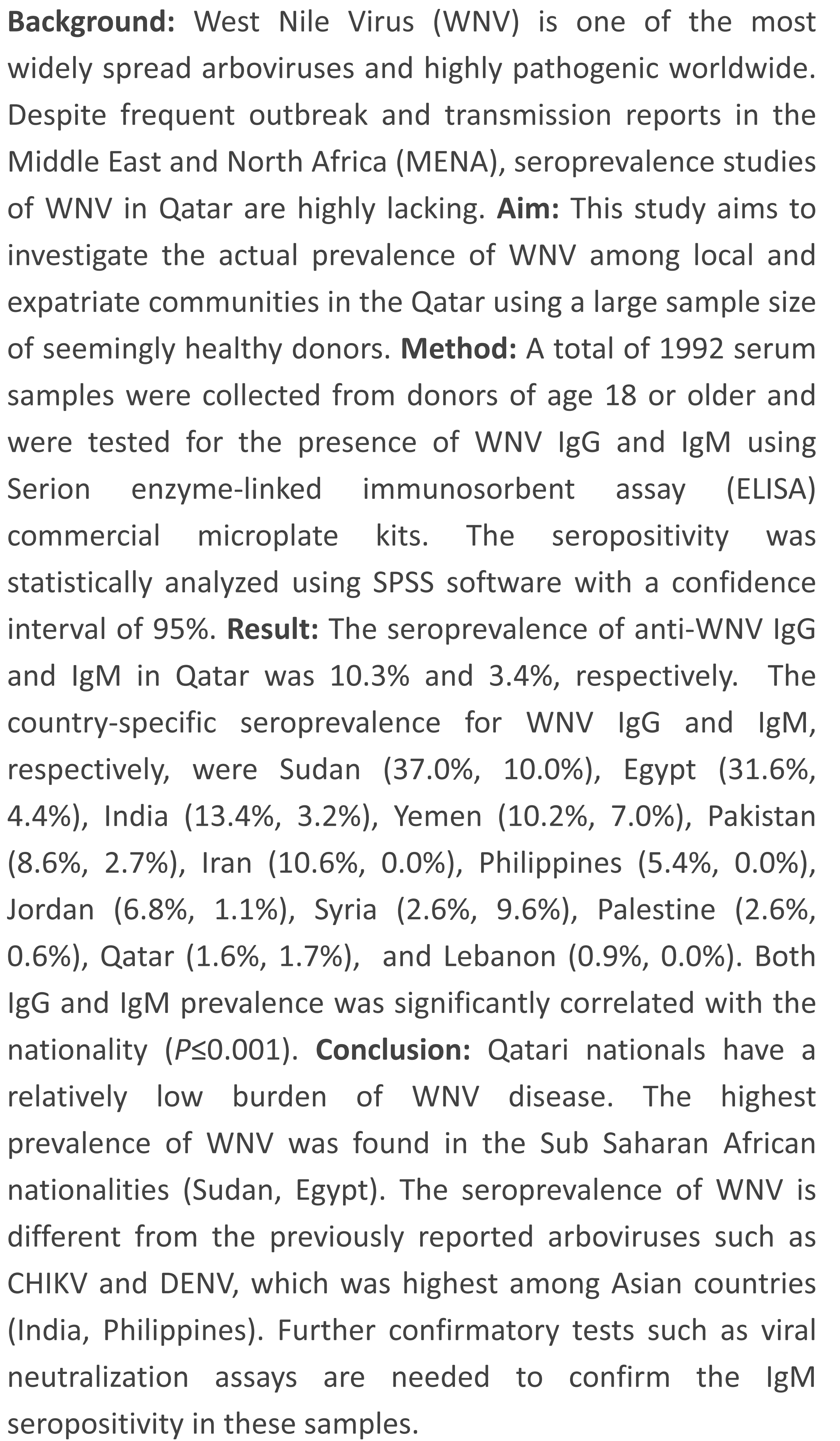 \\
\hline
\end{tabular}

\section{HYPOTHESES AND AIMS}

Based on previous published data regarding CHIKV and DENV in Qatar (2), we hypothesize that WNV is also highly prevalent and associated with certain nationalities residing in Qatar. This study aims to perform serological testing among MENA and non-MENA blood donors living in Qatar to characterize the populations' WNV seroprevalence. The data obtained will better aid the understanding of the seroepidemiology of WNV in these countries and the risk associated with WNV infections in Qatar, particularly through blood donations and organ transplantations.

\section{METHODOLOGY}

Serum Sample Collection from healthy blood donors $(n=1992)$

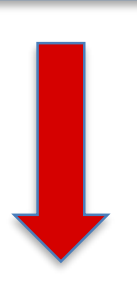

Serum Sample Dilution $1: 100 \mu l$

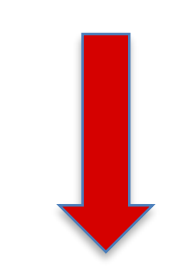

Antibody Detection (IgG, IgM) Using ELISA

\section{RESULTS}

Figure 1. Prevalence of WNV in Qatar

12

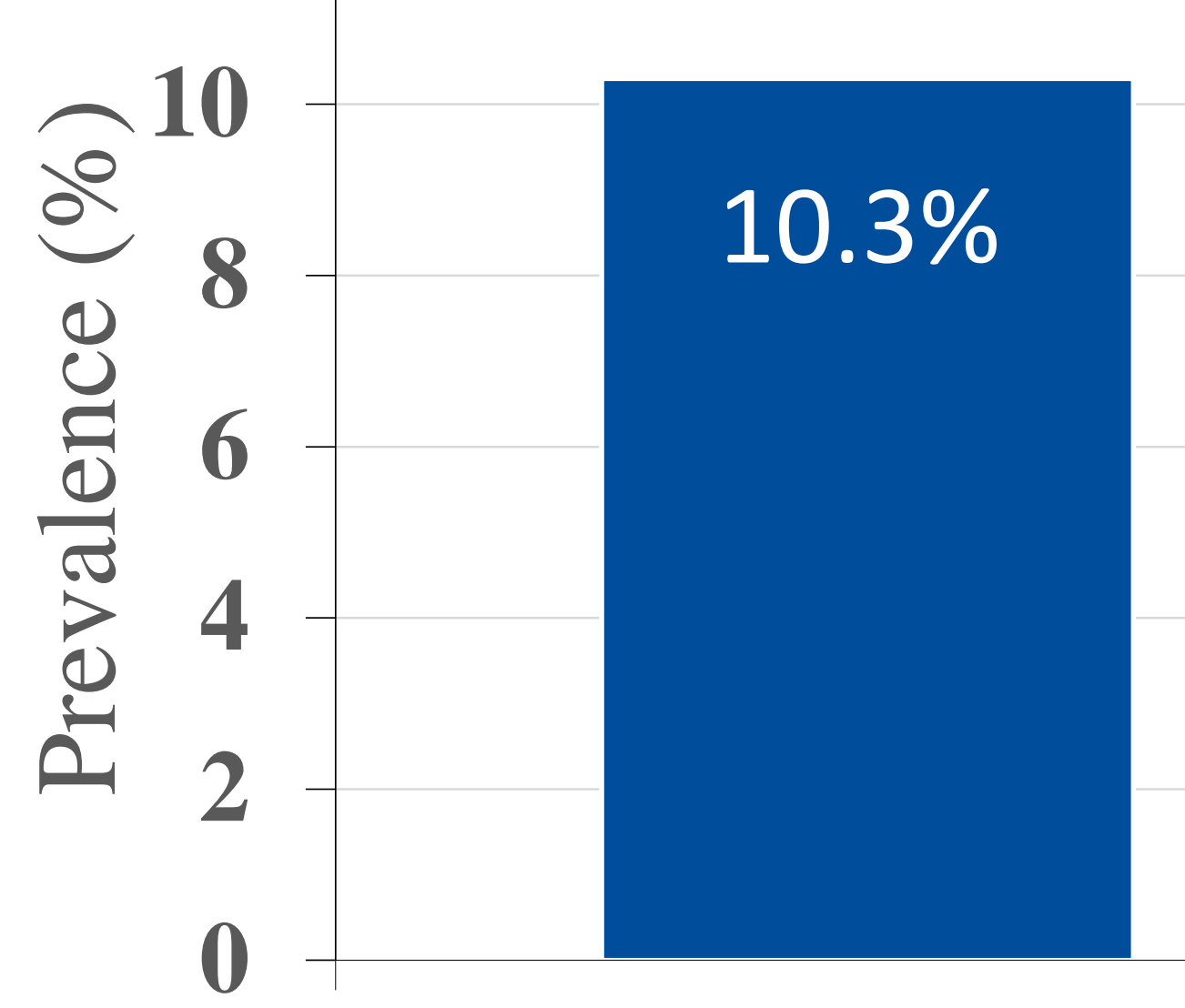

$\operatorname{IgG}$

Antibodies
$3.4 \%$

$\operatorname{IgM}$
Figure 2. Prevalence of WNV in Qatari vs Non-Qatari nationals

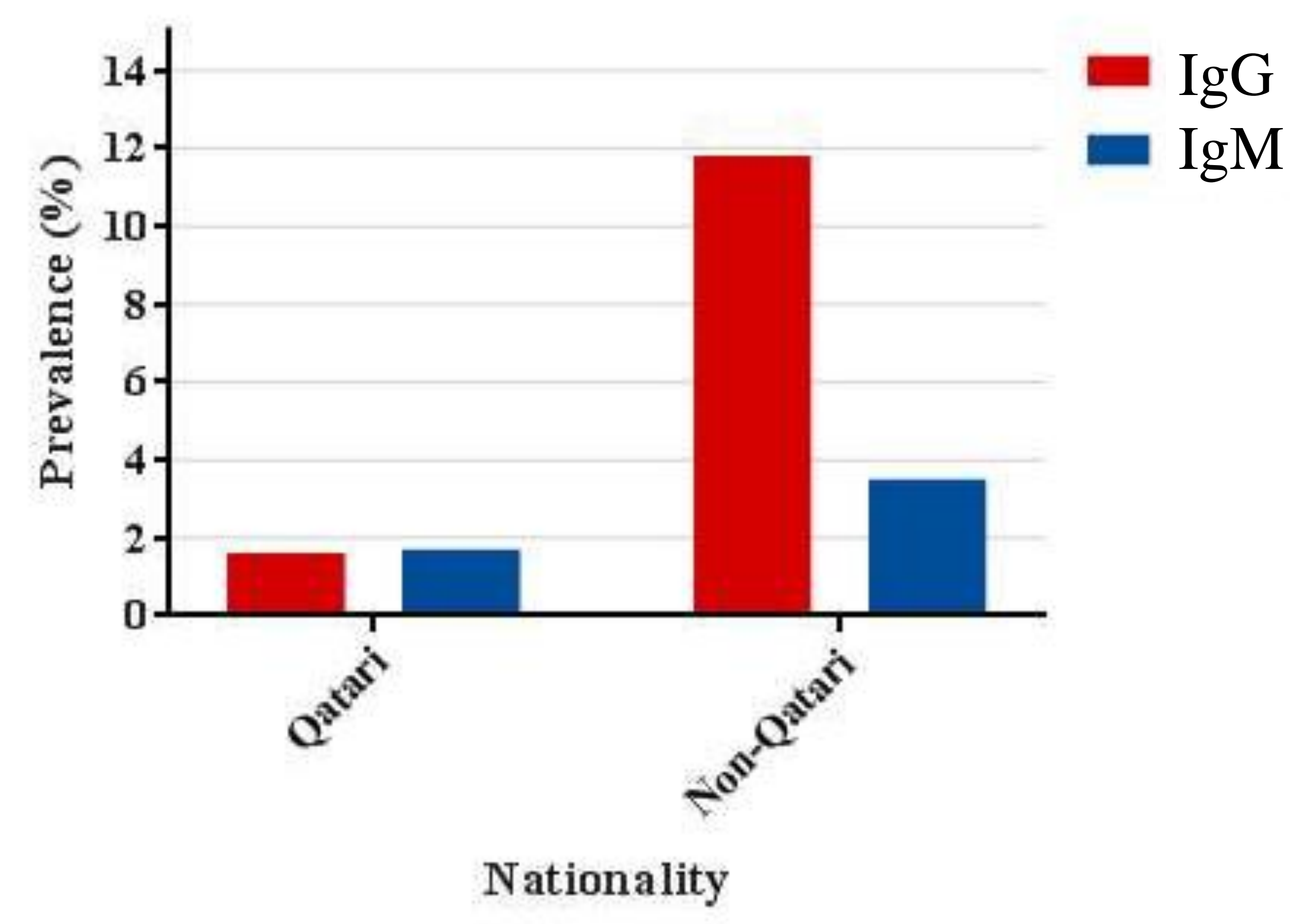

Figure 3. Prevalence of WNV among different nationalities

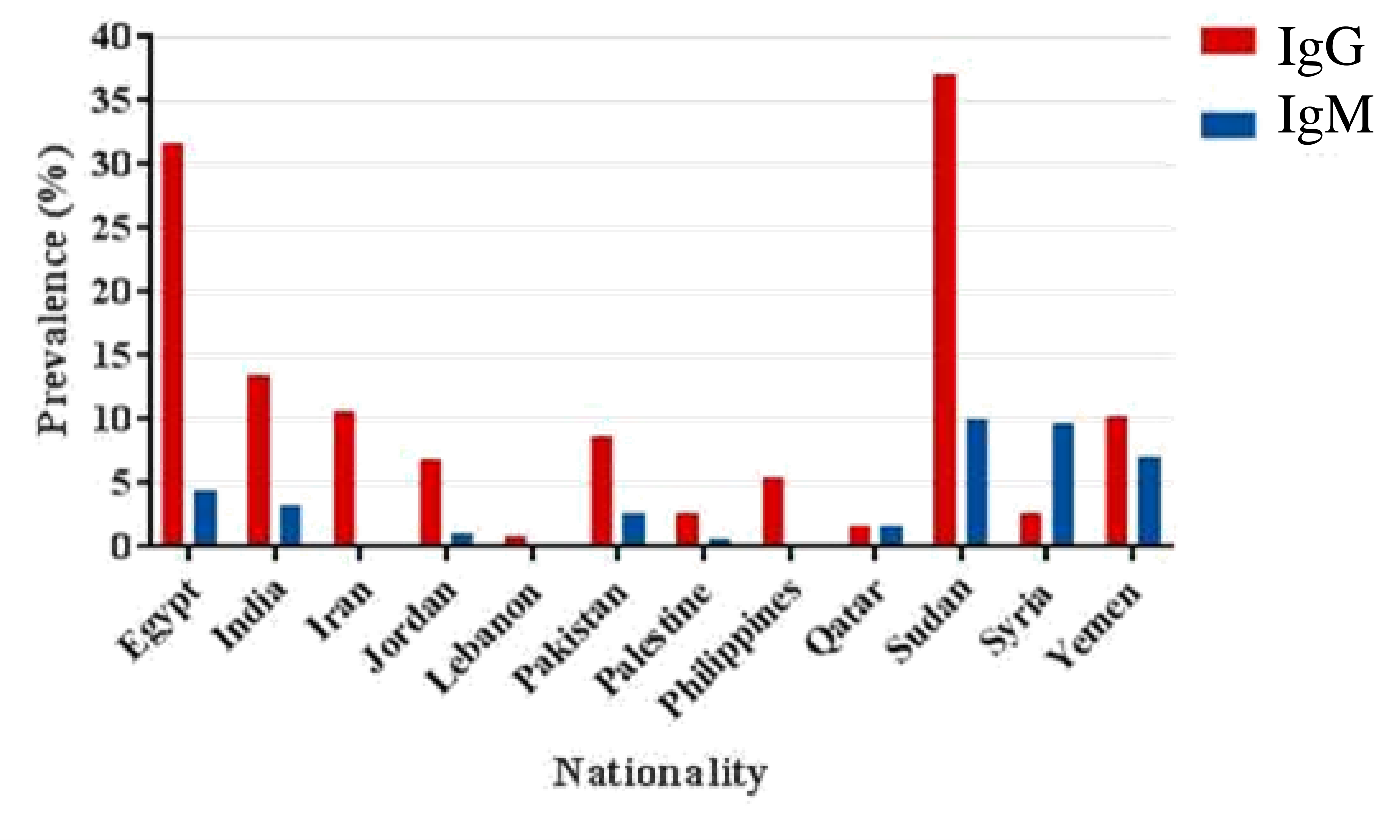

Figure 4. Prevalence of WNV among various age groups

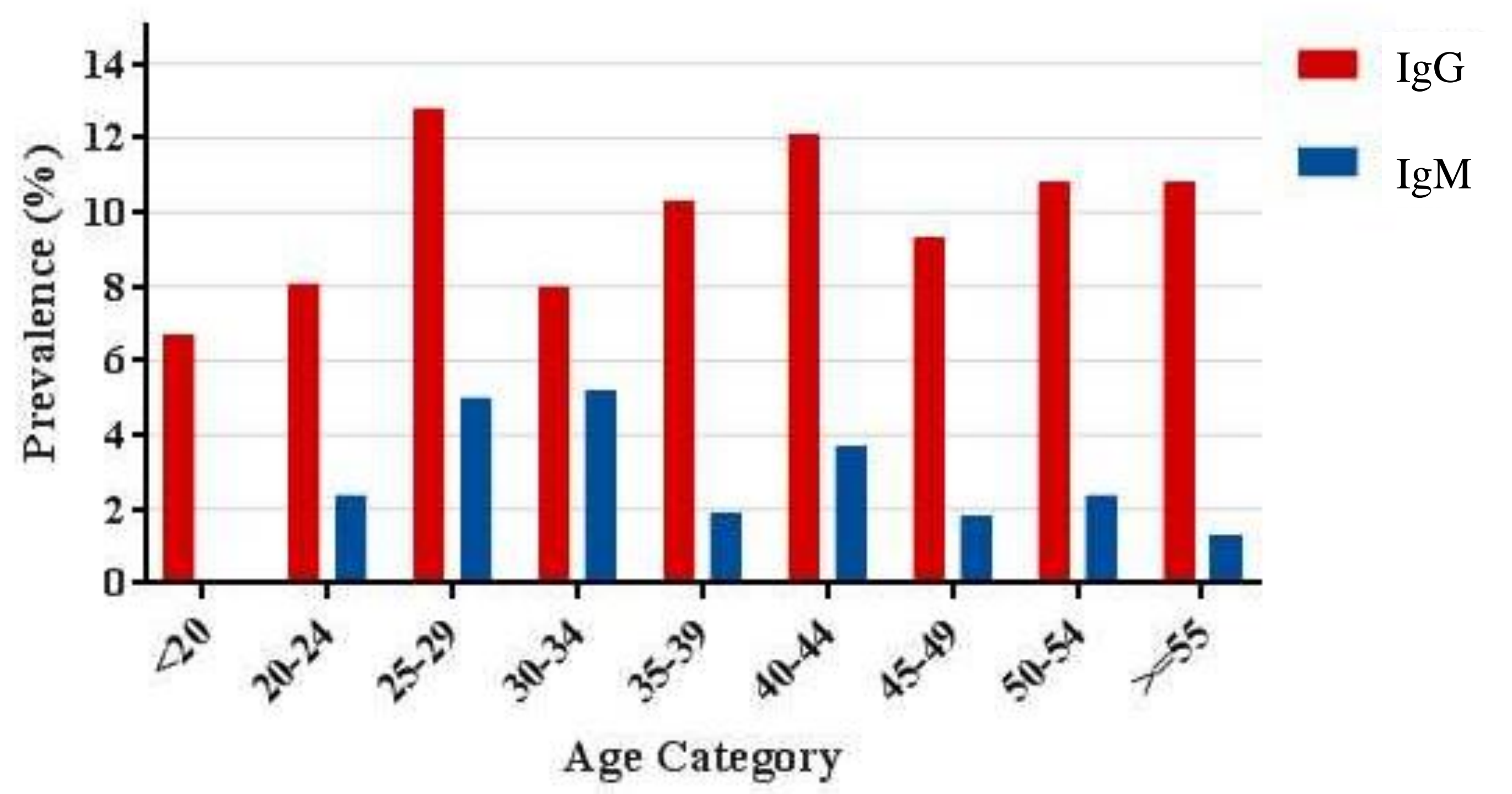

\section{CONCLUSION}

Commercial Serion ELISA classic kits were to test for WNV antibodies in serum samples collected from blood donors in Qatar. A total of 1883 samples for IgG and 1763 samples for IgM were analyzed. The seropositivity results of these samples were statistically analyzed using SPSS statistics software with a confidence interval of $95 \%$ $(\alpha=0.05)$. A total of $10.3 \%$ seropositivity for IgG and $3.4 \%$ seropositivity for IgM was observed. Non-Qatari donors had more positive results for both antibodies than Qatari donors. Among Qatari donors, $1.6 \%$ samples were positive for IgG and $1.7 \%$ samples were positive for IgM. Out of all countries tested, Sudan, closely followed by Egypt, produced highest seroprevalence for WNV IgG of $37.0 \%$ and $31.6 \%$ respectively. These results are validated since these countries fall in Sub-Saharan Africa where WNV is endemic. The highest seroprevalence for WNV IgM was also found among samples from Sudan, with $10.0 \%$ seropositivity. Upon comparison to previously published data, it can be observed that WNV is more prevalent in Sub Saharan Africa unlike CHIKV and DENV which is more prevalent in Asian countries. Our study derived that nationality significantly correlates with WNV seroprevalence with $p$-values of $\leq 0.001$. Age was found to not be significantly correlated to seroprevalence and had a p-value $>0.05$. Due to cross reactivity, ELISA results are not completely dependable and requires further testing using highly specific virus neutralization assays or Western blot procedures. This study emphasizes the importance of screening blood donor samples and recommends conducting further investigations about arboviral diseases in the region.

\section{REFERENCES}

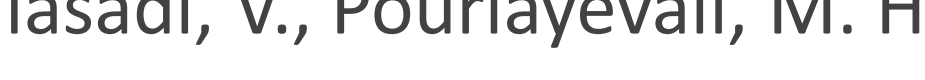
Sadeghi, F., Ahmadi Vasmehjani, A., et al. (2019). Epidemiology of West Nile Virus in the Eastern Mediterranean region: A systematic review. PLoS Negl Trop Dis, 13(1), e0007081.

Humphrey, J. M.., Al-Absi, E. S., Hamdan, M. M., Okasha, S. S., AlTrmanini, D. M., El-Dous, H. G., et al. (2019). Dengue and chikungunya seroprevalence among Qatari nationals and immigrants residing in Qatar. PloS one, 14(1), e0211574-e0211574. $S$ Yousof, Y., E Ahmed, S., H Noor, M., M Nour, M., Saleh, M., Garbi, M., et al. (2018). Seroprevalence of West Nile Virus among Blood Donors at Central Blood Bank, Khartoum State, Sudan (Vol. 4). R Youssef, S., Eissa, D., A Abo-Shady, R., Fouad, N., K Kattab, D. Fathey, $\mathrm{H}$, et al. (2016). Seroprevalence of anti-WNV IgG antibodies and WNV-RNA in Egyptian blood donors: West Nile Virus in Egyptian Blood Donors (Vol. 89).

\section{ACKNOWLEDGEMENT}

First and foremost, this research would not have been possible without the blessings of Almighty Allah. We are grateful to the Biomedical Science Department in Qatar University for giving us the opportunity to conduct this research. We convey our sincere gratitude to our project supervisor, Dr. Gheyath Nasrallah, for his continuous guidance, support, and enthusiasm. It is under his expert supervision that this project was able to reach successful completion. We would also like to thank the members and volunteers at Dr. Gheyath's lab, Enas Al-absi and Layla Mohammed, for their assistance. We also extend our gratitude towards Dr. Soha Dargham of Weill Cornell Medicine-Qatar for her assistance in the statistical analyses of the project. Last but certainly not the least, we would like to express our endless thanks to Duaa AlSadeq for her constant guidance and support. 